\title{
Study of Mechanical Properties and Microstructure of Mercedes-Benz and Local Radiator Material
}

\author{
Usman Sudjadi ${ }^{*}$, Rahmad Jayadiningrat, Erwan Hermawan and Agus Jamaludin \\ Received: July 13, 2020 | Accepted: Aug. 05, 2020 | Published: Dec. 21, 2020 | DOI: 10.22146/jfi.v24i3.57789
}

\begin{abstract}
Indonesia has the capability to produced local products such as vehicle radiators. Many studied were carried out to characterize the radiator material. But it still needs to compare local products and imported products. This study carried mechani-cal properties and microstructure analysis for Marcedes Benz's core radiator and local radiator. The tools used in this study are microhardness tools, optical microscopes, and XRF. The result shows that the Mercedes-Benz radiator binding material before the heat treatment process, using an optical microscope shows the invisible results of a collection of atoms and the matrix and grain boundaries. On local radiator material, Not yet seen the collection of atoms and matrix and grain boundaries. White grains of Mercedes Benz radiator material is more abundant than local radiator materials. Chemical composition test results are; local radiator material content is dominated by three elements $\mathrm{Ca}(26.3 \%), \mathrm{Zn}(44.4 \%)$ and $\mathrm{Cu}(13.9 \%) \mathrm{Cu}$ (2.48\%), Fe (45.15\%), and $\mathrm{Mn}$ (44.88\%). The German Mercedes-Benz element contents are; Fe (28.7), Mn (27.5), Ca (39.2). The hardness of the Mercedes-Benz radiator before heating is $43.4 \mathrm{HV}$, after being heated 39.2 HV. The hardness local radiator material before heating $43.5 \mathrm{HV}$ and after heating $38.2 \mathrm{HV}$.
\end{abstract}

Keywords: Radiator; material; local; microstructure; hardness

\section{INTRODUCTION}

Car performance is influenced by several things, one of which is the quality of the engine coolant or radiator. Radiators have an important role to maintain the temperature of the vehicle because an increase in vehicle temperature will cause engine damage, fuel inefficiency, and increase pollution [1]. Radiators are made with a variety of materials such as irons, steels, aluminum alloys, and bronzes. The quality of the radiator needs to be maintained to avoid failures such as leakage and radiator welds caused by hot cracks [2].

The radiator is used to cool the engine from the combustion process in motorized vehicles, where the principle is to be cooled by passing fluid through the engine block [3]. Based on The Ministry of Trade that imports for the vehicle parts category from 2015 to 2019 , there was a trend of an increase in import value of $24 \%$ [4]. This shows that Indonesia is very dependent

\footnotetext{
${ }^{*}$ Correspondence: umardjasipan@gmail.com

Center For Nuclear Fuel Technology - BATAN, PUSPIPTEK Building

Area.20, Serpong, Tangerang, Indonesia

Full list of author information is available at the end of the article

${ }^{\dagger}$ Equal contributor
}

on imported spare parts components. This condition could impact on the use of local spare part products. Currently, the radiator used in vehicles, especially cars in Indonesia, is dominated by imported products, while local products are difficult to compete with other imported products.

Radiators are widely used in cars though there are also motorbikes that use them. Manufacturing differences affect the quality of the radiator. Be-cause every manufacturer has their standards. The radiator has several components such as core, top, and bottom tank. The core radiator which has an im-portant role as a heat release or cooler [5]. Core Radiator consists of a flat pipe arrangement arranged by a thin plate that serves to release heat. Core Radiator serves to break up the volume of water into smalls pipes passing through the water more easily cool when exposed to the wind from the cooling fan blowing. Radiator cores consist of two types, some made of copper and some made of aluminum [6]. The difference in mechanical properties of the material used in the radiator is influenced by the chemical composi-tion, heat treatment, and microstructure that is formed [7]. 
There has been much research on the testing of radiator materials $[8,9,10]$, interestingly [8] conducted a study on the radiator materials, that the addition of copper to alu-minum would increase the hardness of the material. This shows that each radiator has its own specifica-tions and affects the quality of the radiator. [9] conducted a study of the constituent materials of radiators by using copper and brass alloys, the results showed that differences in composition between the constituent alloys $(\mathrm{Cu}, \mathrm{Sn}, \mathrm{Pb}, \mathrm{Zn}$, and $\mathrm{Fe}$ ) resulted in different mechanical properties. The problem facing today is no research which compares the imported radiator cores and local products, so this study is needed to characterize (hardness test, microstructure test, and chemical composition test) the Mercedez Benz imported car radiators and local product radiators by comparing the quality of local products with imported products based on its chemical composition.

\section{EXPERIMENTAL METHOD}

The materials used in this characterization study are the Mercedez car radiator core material and the local car radiator core material (made in Indonesia). Both of them are used for about 5 years. The first step before testing is to cut into small pieces from each radiator, using the manual method of using a hacksaw to cut and sandpaper to smooth its surface and a ruler to measure its diameter. This manual technique is carried out to get maximum results so that the cut results are suitable that can be used for testing. The diameter of the material to be cut is sized (Length $=1 \mathrm{~cm}$, Width $=1 \mathrm{~cm}$, Thickness $=1 \mathrm{~cm}$ ).

\section{Method and Procedure}

Material mercedez radiator cores made from limp so that the cutting is divided into two parts (core material and core binding material). Core material can be seen in Figure 1a and 1b. This material distribution is carried out to facilitate the testing process, be-cause the Marcedes Benz radiator core material is weak and easily broken. it is difficult to cut in full the size specified for testing, and it is not possible to do a hardness test. So that the radiator core material is only tested for chemical composition, hardness test, chem-ical composition test, and microstructure test.

Material from local radiators has a hard surface and can be sampled for all testing processes, so it does not need to be divided into two parts. Figure 1c shows the results cut local radiator material. Mercedes Benz core radiator samples are only tested for chemical composition. The material then tested by using a hardness test to know the ability of a metal to resist

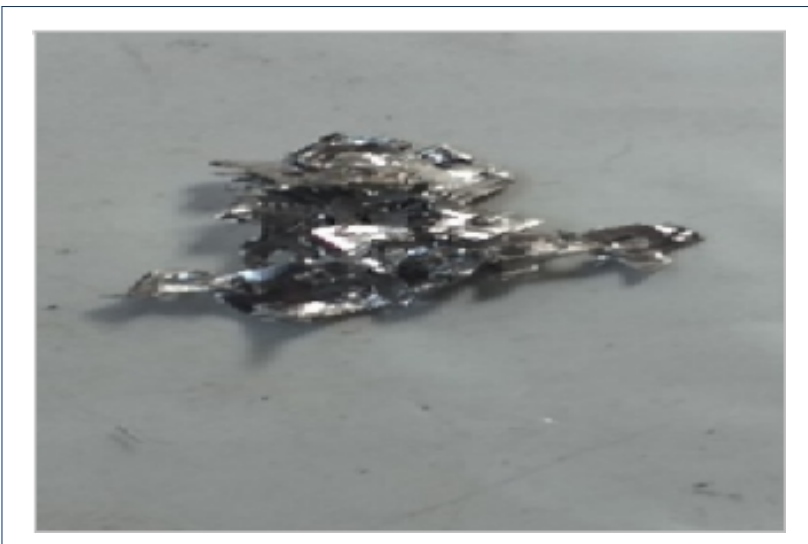

(a)

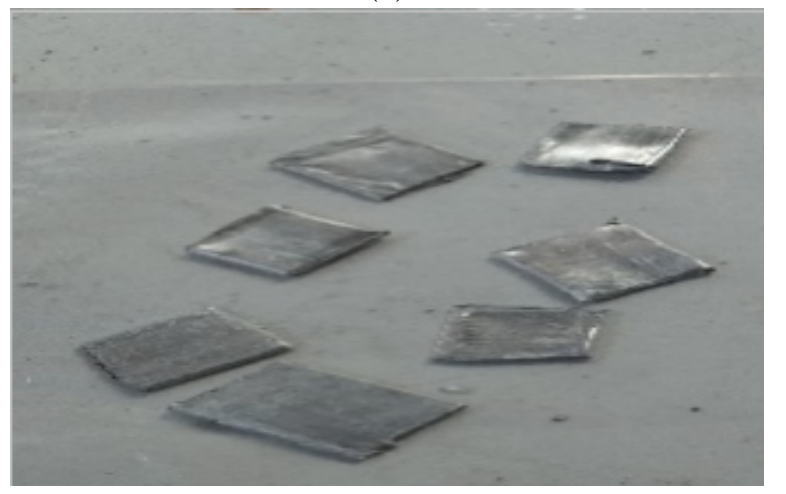

(b)

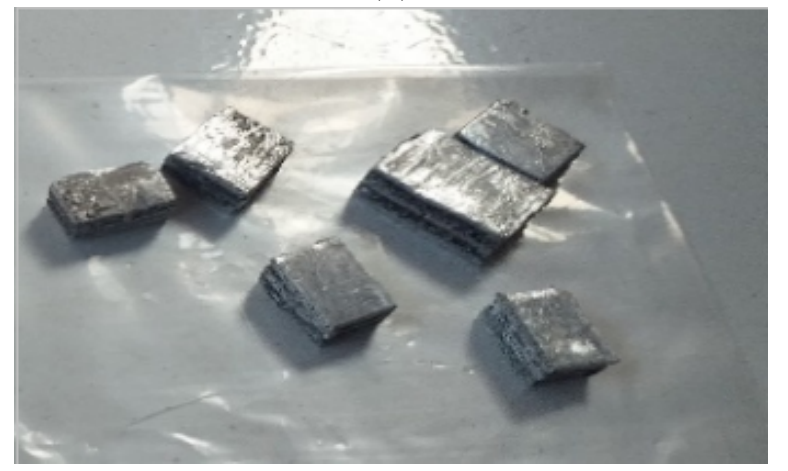

(c)

Figure 1: (a) Mercedes radiator core material sample, (b) Radiator core binder material sample of Marcedes car, and (c) local radiator material sample

permanent indentation [11]. Heat treatment is also carried out on Mercedez binding radiator core and local radiator core samples. The testing technique is carried out in two stages, such as:

- Testing before heat treatmentat, this stage the radiator sample is tested:

1 Microstructure testing using a optical microscope with a magnification of 500x. 
2 Chemical composition test using XRF (X-ray Fluorence). This test was carried out to de-termine the content of chemical elements and the percentage contained in the mer-cedez and local radiator material.

3 Hardness test with Micro-Vickers which aims to determine the average value of hardness of each sample, with a load of 100 grf in 10 seconds.

- Testing after the heat treatment process (samples heated $850^{\circ} \mathrm{C}$, for $\mathrm{t}=3$ hours) After the heat treatment of the radiator material sample is done again testing:

1 Hardness test with Mickey-Vickers uses a load of 100 grf in 10 seconds.

2 microstructure test with 500x magnification.

\section{- Heat treatment}

The heat treatment process is carried out to determine changes in the properties of metals, the diffusion that occurs in the metal affects the changes like the microstructure during the heat treatment process [12]. In this characterization study, heat treatment on each sample of these two types of radiator material with a temperature of $850{ }^{\circ} \mathrm{C}$ within 3 hours, with a normal room temperature cooling process. This heating is quite high (diffusion temperature of atoms). Not the tempering temperature $\left(100-500^{\circ} \mathrm{C}\right)$. Because the sample used has been used for about 5 years. So it has automatically experienced tempering heating of about $1000{ }^{\circ} \mathrm{C}$ during road use. With this high temperature heated. We want to know. Changes in atomic structure due to the self-diffusion of the atoms in the material, and will automatically change the nature of violence and micro-structure.

\section{RESULT AND DISCUSSION}

Microstructure testing is carried out on Mercedes-Benz binding radiator core and local radiator core samples while mercedez radiator core samples cannot be carried out for this test because the material is soft and weak so it is not possible to do this test.

\section{Results of The Microstructure Test Before Heating}

Figure 2a shows the results of the microstructure test on the radiator binder material before the heat treatment process using an optical microscope showed that the atomic matrix and its grain boundaries have not been seen yet. So that this discussion is only qualitative. In the photo you can see a group of white granules and a group of black granules. To find out more clearly the test should be coupled with SEM (Scanning Electron Microscope) and EDX (Energy Dispersive X-Ray) testing. The information will be clearer. At the local raadiator; as well as the results obtained in Figure $2 \mathrm{~b}$ on the local radiator material. Not yet seen the collection of atoms and matrix and grain boundaries, so the discussion is only qualitative. On the local radiator material are visible black elongated lines and a large group of grains. White granules of radiator material are higher than the local radiator material. Large extending lines on the local radiator material are more numerous and larger than the Mercedez Radiator material.

Samples of Mercedes-Benz binder radiator material after heating at temperature $\mathrm{T}=850{ }^{\circ} \mathrm{C}$ for time (t) $=3$ hours. Visible results in a circle around a very black color, like a circular ring. There is some slight white color (see Figure. 2c). While the local radiator material after heating looks. Like a large wheel piece. The color is not too black (see Figure. 2d).

The chemical composition test Marcedes Benz radiator material and local radiator material are done using XRF. Table 1 shows the result of chemical composition test:

Table 1: Comparison of chemical composition of material

\begin{tabular}{|c|c|c|c|c|}
\hline No & Element & $\begin{array}{c}\text { Local } \\
(\%)\end{array}$ & $\begin{array}{c}\text { Mercedes } \\
\text { Banded } \\
(\%)\end{array}$ & $\begin{array}{c}\text { Mercedes } \\
\text { Core } \\
(\%)\end{array}$ \\
\hline 1 & $\mathrm{Al}$ & 0.31 & 0.90 & 2.09 \\
\hline 2 & $\mathrm{~S}$ & 0.045 & - & - \\
\hline 3 & $\mathrm{Ci}$ & 0.07 & - & - \\
\hline 4 & $\mathrm{~K}$ & 0.22 & - & - \\
\hline 5 & $\mathrm{Ca}$ & 26.3 & 39.2 & 0.93 \\
\hline 6 & $\mathrm{Ti}$ & 0.44 & 0.15 & 0.23 \\
\hline 7 & $\mathrm{~V}$ & 0.24 & 0.22 & 0.48 \\
\hline 8 & $\mathrm{Cr}$ & 0.11 & 0.1337 & 0.20 \\
\hline 9 & $\mathrm{Mn}$ & 2.16 & 27.5 & 44.88 \\
\hline 10 & $\mathrm{Fe}$ & 9.96 & 28.7 & 45.15 \\
\hline 11 & $\mathrm{Ni}$ & 0.51 & 0.19 & 0.36 \\
\hline 12 & $\mathrm{Cu}$ & 13.9 & 0.75 & 2.48 \\
\hline 13 & $\mathrm{Zn}$ & 44.4 & 0.94 & 1.42 \\
\hline 14 & $\mathrm{Ga}$ & 1.20 & 1.06 & 1.79 \\
\hline 15 & $\mathrm{Zr}$ & 0.16 & 0.07 & - \\
\hline 16 & $\mathrm{P}$ & - & 0.29 & - \\
\hline
\end{tabular}

The results of the chemical composition test on the core radiator material can be seen in Table 1 local radiator material content is dominated by $\mathrm{Ca}(26.3 \%)$, $\mathrm{Zn}(44.4 \%)$ and $\mathrm{Cu}(13.9 \%)$, in the mercedez radiator core material, 3 the dominant element content is; $\mathrm{Cu}(2.48 \%), \mathrm{Fe}(45.15 \%)$, and $\mathrm{Mn}(44.88 \%)$. And in the German Mercedez radiator material binder, the 3 dominant elements are; Fe (28.7\%), Mn (27.5\%), Ca $(39.2 \%)$.

\section{Hardness Test}

Hardness test uses the microvickers method, the purpose of this hardness test is to determine the hardness value of each core radiator material sample. In this test, a sample of the mercedez binding radiator 


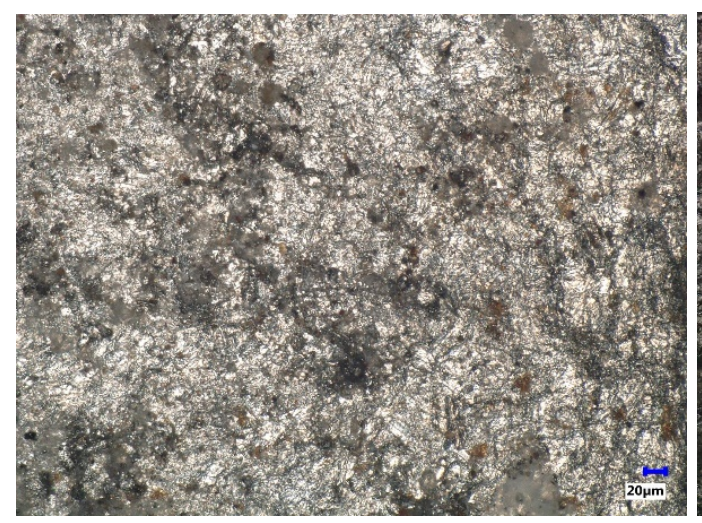

(a)

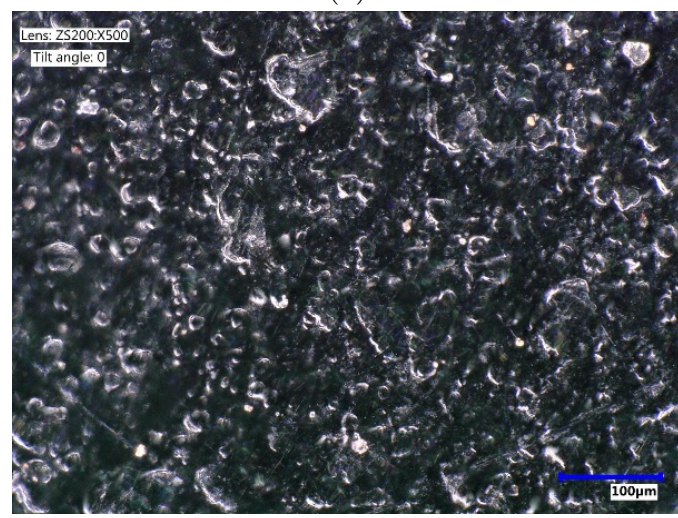

(c)

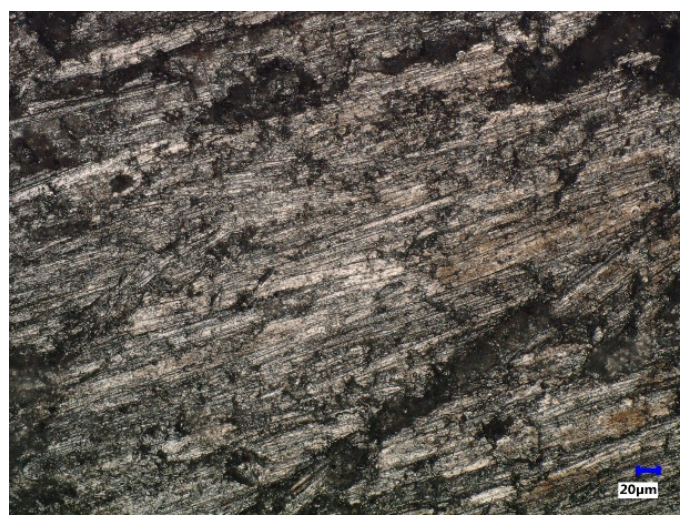

(b)

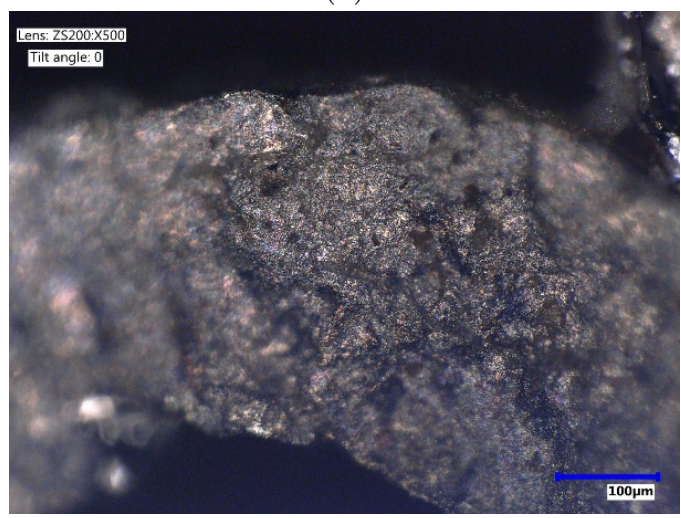

(d)

Figure 2: 500x magnification Mercedes-Benz radiator core before heat treatment, (b) local radiator cores 500x magnification before heat treatment, (c) mercedez radiator core fastening 500x magnification after heat treatment (heated $850{ }^{\circ} \mathrm{C}$ and time $\mathrm{t}=3$ hours), (d) 500x magnification local radiator cores after heat treatment

core cores and local radiator cores, while the mercedez core radiator cores cannot be carried out because the material is soft and weak so it cannot be done for this test. Hardness testing is divided into two parts, (1) hardness test before the heat treatment process and (2) Hardness test after heat treatment.

These two tests are carried out to compare the change in the level of hardness of the material from before the heat treatment process and after the heat treatment process. Micro-vikers hardness test uses 100 grf load in 10 seconds. The following results of the hardness test at two stages of testing:

From Figure 3 above, it can be seen the average value of local radiator material hardness before heat treatment is $43.5 \mathrm{HV}$ and after heat treatment is 38.2 $\mathrm{HV}$ and for Mercedes-Benz radiator binding material before heat treatment is $43.4 \mathrm{HV}$ and after heat treatment $39.2 \mathrm{HV}$.

A decrease in hardness in the local sample after heating with a temperature of $850{ }^{\circ} \mathrm{C}$ for three hours, this is due to the self-diffusion process of the atoms in the Marcedes-Benz or local radiator material [13, 14]. Table 1 shows that the chemical composition of the Marcedes benz radiator material is dominated by Ca, Marcedes benz is Fe, and for the chemical composition of the local radiator material is $\mathrm{Zn}$. Each of the constituent atoms has a different atomic diameter, so that it will affect the mechanism of self diffusion which affects the value of violence.

\section{CONCLUSION}

The microstructure observation of the two types of the material before it is heated, show that the Mercedez radiator binding material before the heat treatment process using an optical microscope shows that the atomic matrix and its grain boundaries are not yet visible. In the photo, can be seen a group of white granules and a group of black granules on the local radiator material. There is no a collection of atoms 


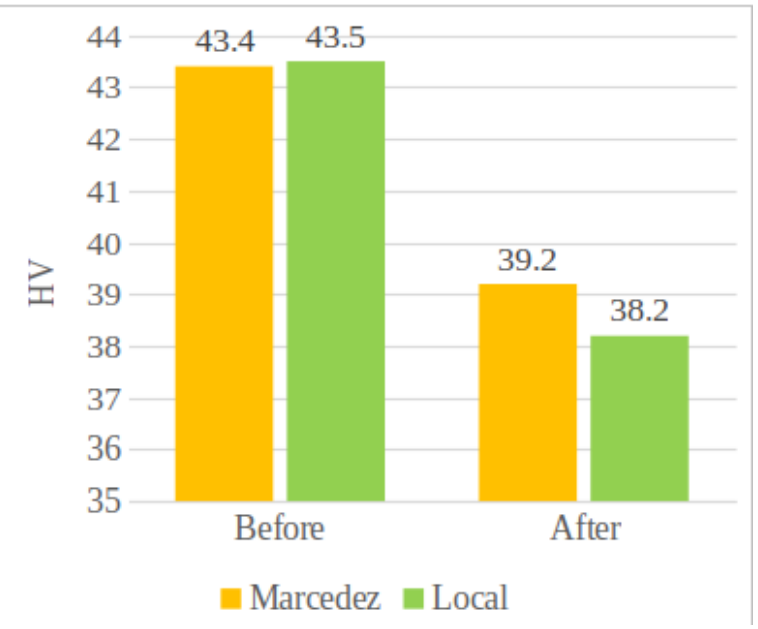

Figure 3: Graph of hardness test results before and after heating $\left(850^{\circ} \mathrm{C}\right.$, for 3 hours $)$.

and matrix and grain boundaries. Only on the local radiator material are visible black elongated lines and a large group of grains. The white grains of Mercedez radiator material are more abundant than local radiator material. Lines extending substantially on local radiator material are more numerous and larger than Mercedez Radiator material. The white grains of Mercedez radiator material is more abundant than the local radiator material. The results of observing the microstructure after the samples are heated 850 oC for 3 hours are; Samples of Mercedez radiator binder material after heating at temperature $\mathrm{T}=850{ }^{\circ} \mathrm{C}$ for $\mathrm{t}=3$ hours. Visible results are circling very black in color, like a circular ring. There are a few shades of white. While the local radiator material after heating looks like a large wheel piece and the color is not too black. The chemical composition test shows that the local radiator material content are dominated by $\mathrm{Ca}(26.3 \%), \mathrm{Zn}(44.4 \%)$ and $\mathrm{Cu}$ $(13.9 \%)$. The Mercedez radiator core material the three dominant element content are; $\mathrm{Cu}(2.48 \%)$, Fe (45.15\%), and $\mathrm{Mn}(44.88 \%)$. And on the German Mercedez radiator material binding, the 3 dominant elemental contents are; Fe (28.7\%), Mn (27.5\%), $\mathrm{Ca}(39.2 \%)$. The hardness of the Mercedez-binding radiator radiator material before heating $43.4 \mathrm{HV}$, after being heated $39.2 \mathrm{HV}$. The hardness for local radiator material before heating 43.5 and after heating $38.2 \mathrm{HV}$.

\section{PENULIS}

1 Usman Sudjadi

Dari :
(1) Center For Nuclear Fuel Technology - BATAN

2 Rahmad Jayadiningrat

Dari :

(1) Master Program in Mechanical Engineering, Engineering Faculty, Mercu Buana University

3 Erwan Hermawan

Dari :

(1) Center For Nuclear Fuel Technology - BATAN

4 Agus Jamaludin

Dari :

(1) Center For Nuclear Fuel Technology - BATAN

\section{References}

1. Elsaid M. Experimental Study On The Heat Transfer Performance and Friction Factor Characteristic of $\mathrm{CO}_{3} \mathrm{O} 4$ and $\mathrm{Al} 2 \mathrm{O} 3$ Based $\mathrm{H} 2 \mathrm{O} /(\mathrm{CH} 2 \mathrm{OH}) 2$ Nanofluids in Vehicle Engine Radiator. Journal of International Communications in Heat and Mass Transfer. 2019;108.

2. Pańcikiewicz K, Radomski W. Lack of Tightness Analysis of Concealed Welded Radiators. Journal of Engineering Failure Analysis. 2020;114.

3. Ramesh J, Ladumor VYG, Araniya KK. A review Paper on Analysis of Automobile Radiator. International Journal of Research and Scientific Innovation. 2014;1(8).

4. of Trade M. Perkembangan Impor Menurut HS 6 Digit; 2020. Available from:

https://statistik.kemendag.go.id/import-growth-hs-6-digits.

5. Prakash RPL, Selvam M, Pandian AAS, Palani S, Harish KA. Design and Modification of Radiator in I. C. Engine Cooling System for Maximizing Efficiency and Life. Indian Journal of Science and Technology. 2016;92:2-9.

6. Dubey AK. Investigation on Suitability of Alumnium to Copper in a Radiator. Journal of Manufacturing Science and Technology. 2015;3(1):16-23.

7. Dwiwandono R, Firmansyah L, Herbirowo S, Hasbi MY, Citrawati F. Analisa Strukturmikro dan Pengaruhnya Terhadap Sifat Mekanis Batangan Rel Tipe R54. Jurnal Metalurgi. 2017;2(67-76).

8. Muthuchamy A, Annamalai R, Acharyya SG, Nagaraju N, Agrawai DK. Microstructureal and Electrocemical Behaviour of Alumuniu Alloy Composites Produced Using Different Sintering Technuques. Journal of Material Research. 2018;21(3):2-7.

9. Jha SK, Balakumar D, Paluchamy R. Experimental Analysis Microstructure and Mechanical Properties of Copper and Brass Based Alloys. International Journal of Automotive and Mechanical Engineering. 2015;11:2317-2331.

10. Fadare DA, Fadara TG, Akanbi OY. Effect of Heat Treatment on Mechanical Properties and Microstructure of NST 37-2 Steel. Journal of Materials Characterization \& Engineering. 2011;10(3).

11. Ismail NM, Khatif NAA, Kecik MAKA, Shaharudin MAH. The effect of heat treatment on the hardness and impact properties of medium carbon steel. IOP Conf Series: Materials Science and Engineering. 2016;11:2-9.

12. Li K, Zhang J, Chen X, Yin Y, He Y, Zhou Z, et al. Microstructure Evolution of Eutectic Si in Al-7Si Binary Alloy by Heat Treatment and Its Effect in Enhanching Thermal Conductivity. Journal of Material Research and Technology. 2020;9(4):8780-8786.

13. Balogh Z, Schmitz G. Diffusion in Metals and Alloys. Journal of Physical Metallurgy. 2014;p. 387-559.

14. Shepelenko M, Klinger L, Rabkin E, Berner A, Prokoshkina D, Reglitz $\mathrm{G}$, et al. Recovery, Recrystallization and Diffusion in Cold-rolled Ni. International Journal of Materials Research. 2015;106:1-11. 